\title{
Comments on 'Sigmoidectomy following sigmoid volvulus: who is at risk of anastomotic failure?'
}

\author{
S. S. Atamanalp ${ }^{1}$ (D)
}

Received: 14 September 2021 / Accepted: 20 October 2021 / Published online: 25 October 2021

(c) Springer Nature Switzerland AG 2021

\section{Dear Sir,}

I read with interest the article written by Tankel et al. [1] on risk factors affecting anastomotic leakage following elective sigmoidectomy and primary anastomosis in patients with sigmoid volvulus (SV). In the light of our 55-year (June 1966-July 2021) and 1040-case experience with SV, which is the largest single-center series in the world [2], I wish to discuss some details in SV management.

First, according to the authors' evaluation, age $>80$ years and American Society of Anesthesiologists (ASA) class 3-4 are associated with an increased risk of anastomotic leakage [1]. Although age alone is a controversial criterion in the elective treatment of SV, it is well known that the high incidence of comorbid diseases in advanced age increases mortality and morbidity [3]. For this reason, I prefer 'life expectancy' as a checkpoint in the decision-making process and I suggest elective surgery in patients $<70-75$ years old [4]. Similarly, a high ASA class $(\geq 4)$ is associated with a high operative mortality of $10-30 \%$ and morbidity of $20-60 \%$. Therefore, I suggest elective surgery in patients in ASA class 1-3 [4]. As an alternative, percutaneous endoscopic colostomy may be performed as an emergency or preferable an elective procedure in patients $>70-75$ years old or in ASA class $\geq 4$, with $5-15 \%$ of mortality and $13-30 \%$ of morbidity rates $[4,5]$.

Regarding surgical practice, I wonder about the indications of elective Hartmann's procedure used in 17 patients $(17.2 \%)$ in the series evaluated by the authors [1]. Although stoma is a life-saving procedure in the emergency surgical treatment of selected high-risk, bed-bound, and elderly patients [4], sigmoidectomy and primary anastomosis,

S. S. Atamanalp

ssa@atauni.edu.tr

1 Department of General Surgery, Faculty of Medicine, Ataturk University, 25040 Erzurum, Turkey preferably laparoscopic, is preferable in the elective surgical treatment of SV [3].

I congratulate the authors for their informative research and I await their response.

Funding None.

\section{Declarations}

Conflict of interest The author declares that he has no conflict of interest.

Ethical approval This article does not contain any studies with human participants performed by the author.

Informed consent For this form of study, formal consent is not required.

\section{References}

1. Tankel J, Gilstein H, Neymark M, Zuckerman M, Spira R, Yellinek S (2021) Sigmoidectomy following sigmoid volvulus: who is at risk of anastomotic failure? Tech Coloproctol. https://doi.org/ 10.1007/s10151-021-02508-6

2. Atamanalp SS (2019) Sigmoid volvulus: the first one thousandcase single center series in the world. Eur J Trauma Emerg Surg 45:175-176. https://doi.org/10.1007/s00068-017-0859-6

3. Alavi K, Poylin V, Davids JS, Patel SV, Felder S, Valente MA et al (2021) The American Society of Colon and Rectal Surgeons clinical practice guidelines fort he management of colonic volvulus and acute colonic pseudo-obstruction. Dis Colon Rectum 64:1046-1057. https://doi.org/10.1097/DCR.0000000000002159

4. Atamanalp SS (2020) Sigmoid volvulus: an update for Atamanalp classification. Pak J Med Sci 36:1137-1139. https://doi.org/10. 12669/pjms.36.5.2320

5. Jackson S, Hamed MO, Shabbir J (2020) Management of sigmoid volvulus using percutaneous endoscopic colostomy. Ann R Coll Surg Engl 102:654-662. https://doi.org/10.1308/rcsann.2020.0162

Publisher's Note Springer Nature remains neutral with regard to jurisdictional claims in published maps and institutional affiliations. 